Преступления, совершенные

медицинскими работниками вследствие ненадлежащего исполнения своих профессиональных обязанностей (по материалам судебной практики Европейской части России 2015-2017 г.г.)

\author{
Гришин С. М. \\ к.ю.н., адвокат Московской коллегии адвокатов, преподаватель Национального \\ исследовательского университета "Высшая школа экономики»
}

\begin{abstract}
Аннотация
В статье на основе фактических материалов рассмотрена проблема преступлений, явившихся следствием ненадлежащего исполнения медицинскими работниками своих профессиональных обязанностей. Анализируются недостатки криминальной статистики, не позволяющие создать целостную картину ситуации, складывающейся в стране в указанной области, отмечаются трудности с выявлением подобных преступлений и привлечением нарушителей к уголовной ответственности. Приводится разбор отдельных приговоров в отношении врачей, по вине которых погибли пациенты. Делается вывод о несоответствии действующего уголовного законодательства объективным потребностям охраны прав пациента, формулируются предложения по повышению эффективности судебно-медицинских экспертиз по уголовным делам о профессиональных преступлениях медицинских работников.
\end{abstract}

Ключевые слова: преступления с тяжкими последствиями, медицинские работники, статистика преступлений, врачебная ошибка, судебно-медицинская экспертиза

doi: 10.29234/2308-9113-2018-6-1-1-14

В последние годы произошли существенные изменения, как в жизни нашего общества, так и во взаимоотношениях врача и пациента.

Внедрение рыночных отношений во все сферы деятельности в нашей стране, проводимые реформы, не могли не отразиться и на здравоохранении, а научнотехнический прогресс и вся совокупность современных общественных отношений предъявляют все более высокие профессиональные, морально-этические и правовые требования к специалистам сферы здравоохранения.

В условиях складывающейся социально-экономической ситуации в нашей стране приходится пересматривать огромное количество понятий и ценностей. Отношения врача и пациента перестают быть межличностными. Все более вырисовывается их правовая сторона.

Не вызывает сомнения и то, что с оказанием медицинской помощи непосредственно связана проблема возникновения профессиональных ошибок и дефектов оказания медицинской помощи. 
Заметным становится и рост преступлений с тяжкими последствиями, совершаемых лицом вследствие ненадлежащего исполнения своих профессиональных обязанностей. За последние годы существенно возросла доля причинения смерти и тяжкого вреда здоровью человека медицинскими работниками, лицами, призванными охранять эти ценности.

В существующей юридической практике под ответственностью понимают применение к лицу, совершившему правонарушение, предусмотренных законом мер принуждения. Профессор Ю. Д. Сергеев указывает: «Совершение преступления медицинским работником в ходе своей профессиональной деятельности является квалифицирующим обстоятельством и, как следствие, предусматривает повышенную ответственность» [9].

Под уголовной ответственностью следует понимать меры принудительного характера, которые предусматриваются уголовным законом в качестве реакции государства на совершение лицом преступления. В соответствии с Уголовным кодексом РФ (далее - УК РФ) лицо подлежит уголовной ответственности только за те опасные последствия, в отношении которых установлена его вина. Уголовная ответственность за невиновное причинение вреда, не допускается. Виновным в преступлении признается лицо, совершившее деяние умышленно или по неосторожности.

Стоит обратить внимание на то, что причинение вреда здоровью легкой или средней тяжести, вследствие ненадлежащего исполнения медицинским работником своих служебных обязанностей по неосторожности, уголовной ответственности не влекут. Таким образом, под профессиональным преступлением в медицинской деятельности понимается умышленное или по неосторожности совершенное лицом медицинского персонала в нарушение своих профессиональных обязанностей такое общественно опасное деяние, которое причинило (или реально могло причинить) существенный вред здоровью отдельных граждан или вызвало опасность для их жизни [10].

Уголовная ответственность не наступает, если при неблагоприятном исходе лечения действия медицинского работника были правильными, если он сделал все, что следовало сделать в данной ситуации; если медицинский работник не мог предвидеть, что его действия являются неправильными; если при объективно неправильных действиях не наступили вредные последствия или же отсутствует причинная связь между действиями и наступившими последствиями; эти объективно неправильные действия способствовали наступлению неблагоприятных последствий - это или смерть больного или причинение существенного вреда здоровью (причинная связь носит не случайный, а необходимый характер). При отсутствии хотя бы одного из указанных условий ответственность медицинского работника исключается.

В соответствии с действующим уголовным законодательством медицинский работник может нести уголовную ответственность за следующие виды возможных в его профессиональной практике преступлений: убийство (ст. 105 УК РФ); причинение смерти 
по неосторожности вследствие ненадлежащего исполнения лицом своих профессиональных обязанностей (ч. 2 ст. 109 УК РФ); причинение тяжкого вреда здоровью по неосторожности, совершенное вследствие ненадлежащего исполнения лицом своих профессиональных обязанностей (ч. 2 ст. 118 УК РФ); принуждение к изъятию органов или тканей человека для трансплантации (ст. 120 УК РФ); заражение другого лица ВИЧинфекцией вследствие ненадлежащего исполнения лицом своих профессиональных обязанностей (ч. 4 ст. 122 УК РФ); незаконное производство аборта (ст. 123 УК РФ); неоказание помощи больному (ст. 124 УК РФ); незаконное помещение в психиатрический стационар (ст. 128 УК РФ); нарушение неприкосновенности частной жизни (ч. 1 ст. 137 УК РФ); подмена ребенка (ст. 153 УК РФ); незаконное приобретение, хранение, перевозка, изготовление, переработка наркотических средств, психотропных веществ или их аналогов, а также незаконное производство, сбыт или пересылка указанных веществ (ст. 228 УК РФ); хищение либо вымогательство наркотических или психотропных веществ (ст. 229 УК РФ); незаконная выдача либо подделка рецептов или иных документов, дающих право на получение наркотических средств или психотропных веществ (ст. 233 УК РФ); незаконный оборот сильнодействующих или ядовитых веществ в целях сбыта (ст. 234 УК РФ); незаконное занятие частной медицинской практикой или частной фармацевтической деятельностью (ст. 235 УК РФ); нарушение санитарно-эпидемиологических правил (ст. 236 УК РФ); сокрытие информации об обстоятельствах, создающих опасность для жизни или здоровья людей (ст. 237 УК РФ). За служебные преступления медицинские работники могут нести ответственность как должностные лица по статьям главы 30 УК РФ «Преступления против государственной власти, интересов государственной службы и службы в органах местного самоуправления» и как лица, выполняющие управленческие функции в управленческой или иной организации по статьям главы 23 УК РФ «Преступления против интересов службы в коммерческих или иных организациях». При этом, решая вопрос об уголовной ответственности медицинского работника, правоохранительные органы должны устанавливать какие обязанности он выполняет, дабы не допустить отожествления профессиональных функций с должностными и управленческими.

Среди преступлений наибольший удельный вес имеют неосторожные, совершенные вследствие ненадлежащего исполнения лицом своих профессиональных обязанностей: причинение тяжкого вреда здоровью по неосторожности, (ч. 2 ст. 118 УК РФ), причинение смерти (ч. 2 ст. 109 УК РФ), заражение другого лица ВИЧ-инфекцией (ч. 4 ст. 122 УК РФ), а также неоказание помощи больному (ст. 124 УК РФ).

К преступлениям медицинских работников против жизни и здоровья, совершаемым с прямым умыслом, можно отнести убийство в целях использования органов и тканей потерпевшего (п. «М» ч. 2 ст. 105 УК РФ), умышленное причинение тяжкого вреда здоровью в целях использования органов и тканей потерпевшего (п. «ж» ч. 2 ст. 111 УК РФ), причинение средней тяжести и легкого вреда здоровью (ст. 112, 115 УК РФ), незаконное производство аборта (ст. 123 УК РФ), к совершаемым с косвенным умыслом заражение другого лица ВИЧ-инфекцией (ч. 4 ст. 122 УК РФ). 
Согласно Федеральному закону от 29.11.2007 N 282-Ф3 «Об официальном статистическом учете и системе государственной статистики в Российской Федерации», а также изданным распоряжением Правительства РФ от 06.05.2008 N 671-р «Об утверждении Федерального плана статистических работ» (вместе с «Федеральным планом статистических работ») (далее - Федеральный план) сведения относительно количества преступлений против жизни и здоровья, совершаемых медицинскими работниками, не относятся к официальной статистической отчетности, установленной Росстатом.

В силу п. 3.8 Федерального плана субъектом официального статистического учета, осуществляющим формирование $и$ предоставление пользователям официальной статистической информации о зарегистрированных, раскрытых $и$ нераскрытых преступлениях является Министерство внутренних дел РФ. В формах федерального и ведомственного статистического наблюдения как МВД России, так и СК России сведения о медицинских работниках, подозреваемых (обвиняемых) в совершении преступления, отдельно не отражаются.

На практике статистика преступлений в России не в полном объеме учитывает совершенные преступления. Здесь не фиксируются противоправные действия рецидивного или смежного характера. Часто люди и сами не заявляют о случаях криминальных действий, жертвами или свидетелями которых они становятся, например, из-за неверия в объективное расследование. По данным ВЦИОМ эта цифра составляет более $49 \%$ [2].

Вся статистика преступлений в России имеет ведомственный характер. Следовательно, статистика совершенных преступлений имеет определенную погрешность, связанную с искажением ее теми органами, которые ведут учет.

Однако, судя по данным ряда бюро судебной медицинской экспертизы Европейской части России, количество уголовных дел, возбуждаемых против врачей, явно растет. Об этом свидетельствуют и результаты опроса граждан и работников правоохранительных органов. Последние вообще считают, что доля зарегистрированных преступлений медицинских работников составляет лишь 10\% от фактически совершенных.

Практические работники испытывают серьезные трудности с выявлением этих преступлений, формированием доказательственной базы, квалификацией таких деяний и привлечением нарушителей к уголовной ответственности. Во многом это объясняется объективными трудностями установления причинной связи между действием (бездействием) медицинского работника и наступившими общественно опасными последствиями. Препятствует раскрытию преступлений и организация проведения судебно-медицинской экспертизы по факту правонарушения медицинского работника. По мнению опрошенных работников правоохранительных органов, нередко при составлении заключения судебно-медицинской экспертизы ложно понятые ведомственные интересы, чувства коллегиальности и корпоративности преобладают над интересами законности. 
По данным литературы Всемирная организация здравоохранения допускает и считает нормой 9\% ошибок при оказании медицинской помощи. В Российской Федерации при проведении экспертизы частота выявления дефектов при оказании медицинской помощи значительно превышает допустимое значение и соответствует 35\% [11].

В России в 2015 году из-за врачебных ошибок и ненадлежащего оказания медицинской помощи погибли более 700 человек, среди которых 317 детей, сообщил председатель Следственного комитета России (далее - СК РФ) Александр Бастрыкин, выступая на заседании коллегии по вопросам организации работы по расследованию преступлений, связанных с некачественным оказанием медпомощи.

«В 2015 году потерпевшими от ятрогенных преступлений признаны 888 человек. Из них вследствие врачебных ошибок и ненадлежащего оказания медицинской помощи погибло 712 человек, в том числе 317 детей. В 2016 году из 352 человек, погибших вследствие врачебных ошибок и ненадлежащего оказания медицинской помощи, - 142 ребенка», приводит пресс-служба СК слова А. Бастрыкина.

Он также уточнил, что в первом полугодии 2016 года в органы СК РФ поступило более 2,5 тысяч сообщений о преступлениях, связанных с врачебными ошибками и ненадлежащим оказанием медицинской помощи, по результатам их рассмотрения возбуждено 419 уголовных дел.

Можно предположить, что приведенная статистика представляет собой лишь «верхушку айсберга». Ведь если даже больной скончался, и не в последнюю очередь от ненадлежащего оказания медицинской помощи, далеко не факт, что его родственники начнут писать жалобу в прокуратуру. Чаще всего они пишут другое заявление - на имя главврача, с просьбой выдать тело для погребения без вскрытия, с припиской, что «никаких претензий к оказанной медпомощи не имеем». Ну а после того, как тело усопшего родственника погребено, без патологоанатомической экспертизы дать ход серьёзному расследованию просто немыслимо.

Стоит отметить, что в других странах ситуация не лучше. В Великобритании ежегодно умирают по этой причине около 70 тысяч человек, в Германии - 25 тысяч... [14].

Справедливости ради стоит заметить, что подобные цифры назвать официальными трудно. В Международной классификации болезней 10-го пересмотра среди причин смерти такого диагноза, как «врачебная ошибка», просто нет. Стало быть, способы учёта этого неприятного явления лишь косвенные. А именно - расхождения патологоанатомических диагнозов (после вскрытия тела умершего) с клиническими, судебные иски пациентов о компенсации нанесенного ущерба с сопутствующей экспертизой, а также уголовные дела по «медицинским статьям». 
А потому, по неофициальной статистике, число умерших из-за врачебных ошибок пациентов в России, достигает 100 тысяч человек в год. Другое дело, что меньше одного процента таких случаев доходит до следователей.

«Для того чтобы оперативно получать информацию о совершенных ятрогенных преступлениях, председатель СК РФ указал подчиненным на необходимость заключения соглашений о сотрудничестве с Росздравнадзором, который осуществляет контроль и за порядком проведения медицинской экспертизы, и за соблюдением стандартов качества медицинской помощи», - говорится в сообщении пресс-службы СК.

Кроме того, А. Бастрыкин отметил опыт взаимодействия с региональными департаментами здравоохранения, которые В рамках соглашений информируют следственные управления обо всех фактах смертей несовершеннолетних, беременных и рожениц. Как заявил А. Бастрыкин, подобные соглашения заключены уже в 27 следственных управлениях, еще в 15 проходят согласование.

Но самое главное - если пересажать (или даже просто уволить) всех «плохих врачей», то кто вместо них работать будет? Дефицит кадров, как минимум, врачей первичного звена, тех самых «участковых», в России просто страшный.

Глава Минздрава Вероника Скворцова привела на днях неутешительную статистику: в Российской Федерации не хватает более 40 тыс. врачей. Специалисты не хотят работать в существующей системе здравоохранения. Ежегодно до 10\% врачей уходят из профессии, причем только 2\% - на пенсию, остальные ищут себя в других отраслях. Например, по данным московских властей, в 2017 году в столице не хватало 7,5 тысяч участковых педиатров, в Ярославской детской поликлинике им. Семашко 6,5 тысяч детишек обслуживают аж целых 4 врача (при норме на одного в 800 человек), в Кировской области только официально не заполнены 27 вакансий педиатров - с зарплатой в 14 тысяч рублей в месяц [8,12].

За последнее десятилетие возросло число преступлений, совершаемых медицинскими работниками в процессе осуществления своих профессиональных обязанностей.

В первую очередь это связано с преступной небрежностью и легкомыслием отдельных медицинских работников, их безответственностью и безразличным отношением к судьбе пациентов, вверивших им свою жизнь и здоровье. Сказывается и низкий уровень подготовки медицинских работников, бесконтрольность деятельности лечебных учреждений со стороны Минздрава России.

По статистике СК РФ, сегодня в каждом регионе страны расследуются десятки смертей пациентов, в которых подозревают врачей. Чаще всего медикам вменяют две статьи УК РФ - 109-ю «причинение смерти по неосторожности» и 293-ю «халатность». 
В СК РФ проанализировали уголовные дела против медиков и выяснили, что смертельные ошибки происходят все чаще. Другой вывод исследования - расследование таких дел растягивается иногда на годы, а судебные приговоры поражают своей мягкостью. Этому есть объяснение в несовершенстве действующего законодательства.

Недавно в Москве вступил в силу приговор хирургу, по вине которого умерла 28-летняя пациентка. Эксперты установили, что смерть на операционном столе наступила из-за передозировки обезболивающего. Суд признал хирурга виновным. Но врач не сел за решетку. Приговор - 2 года ограничения свободы.

В Воронежской области врач «скорой» выехал по вызову. Звонившая женщина объяснила, что муж не может дышать и у него боли в груди. Доктор, как потом доказал Следственный комитет, толком не осмотрел пациента, быстро поставил диагноз - «остеохондроз» и посоветовал идти к участковому. Под утро, когда мужчине стало совсем плохо, жена опять вызвала «скорую». Но доктор просто отказался ехать. Послал вместо себя фельдшера. Она и констатировала смерть мужчины от острого инфаркта. Суд дал доктору два года, но условно.

В Мордовии, в городе Темников, прохожие вызвали «скорую», увидев лежащего на тротуаре человека. «Скорая» привезла гражданина в больницу, а доктор велела положить его в коридоре. Больше к нему никто не подошел и не осматривал, а на следующий день нашли его в койке мертвым. Следствию доктор объяснила: она решила, что это пьяница, который в лечении не нуждается. А вскрытие показало, что умерший был совершенно трезв и из-за тяжелой болезни потерял сознание. Приговор - врач виновна в смерти человека, наказание - полтора года условно.

В Чувашии изобрели новый диагноз. Там в Красноармейскую больницу привезли пациентку. У женщины был острый приступ панкреатита и сахарный диабет. Местный доктор в графе «диагноз» записал - «Злоупотребление алкоголем». Сейчас следователи говорят, что погибшую можно было легко спасти, если бы диагноз медик определил верно. Доктор приговорена к одному году и десяти месяцам колонии-поселения.

В Пермском крае закончилось следствие против старшей медсестры Березниковской городской больницы. В эту клинику поступила 5-летняя девочка с переломом носа. Ей провели операцию. Медсестра во время операции ошиблась так, что ребенку пришлось ампутировать левое предплечье. Экспертизу из-за особой сложности пришлось делать в столице. Сейчас дело в суде.

Число судебных исков к медицинским работникам в Татарстане растёт. Но далеко не всегда уголовные дела удаётся довести до суда [1].

В 2016 году в отношении медиков было возбуждено 39 уголовных дел. При этом до суда дошло только $6 .$. 
36-летний мужчина в течение месяца лечился в стационаре Сабинской ЦРБ, но заведующий хирургическим отделением несвоевременно диагностировал у него язву желудка и не принял решение о проведении экстренной операции. В результате массированного кровотечения больной скончался. На суде заведующий до последнего слова не признавал своей вины, но когда он понял, что обвинительный приговор неминуем, сообщил, что готов возместить моральный ущерб в размере 500 тыс. рублей. Судья прекратил дело в связи с примирением сторон. Вот пример урегулирования вопроса в интересах обеих сторон. Но приговор с реальным сроком лишения свободы это крайняя мера. Ведь врач в 99\% случаев не совершает умышленное преступление, он допускает ошибку. Лишение права заниматься медицинской деятельностью и адекватная денежная компенсация - уже серьёзное наказание.

В Актанышском районе г. Казани врач женской консультации вовремя не госпитализировал беременную женщину, выбрал неверную тактику родоразрешения без проведения терапии. В результате женщина и плод погибли. Экспертиза выявила прямую причинную связь между действиями медика и летальным исходом, но, несмотря на это, суд приговорил врача к штрафу всего в 50 тысяч рублей. И Верховный суд Республики Татарстан согласился с этим решением [1].

В Воронеже суд вынес приговор 62-летнему бывшему нейрохирургу больницы «Электроника», которого признали виновным в гибели пациента.

Днём 25 июля 2015 года в медучреждение доставили 27-летнего мужчину с травмами после ДТП. Его госпитализировали в нейрохирургическое отделение больницы, так как посчитали, что сильнее всего у пациента задета голова. На следующий день молодой мужчина скончался.

Согласно заключению экспертов, смерть наступила от развившихся тяжёлых осложнений после тупой травмы живота. Специалисты отметили, что лечение было начато слишком поздно: прошло более 19 часов с того момента, когда пациент поступил в больницу. А осложнения - то есть, перитонит - развились из-за несвоевременно проведённой диагностики: дежурный врач так и нашёл времени осмотреть пациента, отправить его на УзИ и анализы. Эксперты указали, что именно бездействие дежурного врачанейрохирурга привело к смерти мужчины.

В региональном СК отметили, что во время следствия врач не признавал свою вину.

«Следователями собрана исчерпывающая доказательственная база, в основу которой легли показания свидетелей, заключения проведённых судебных экспертиз, в том числе комплексных судебно-медицинских экспертиз, протоколы следственных действий, а также иные материалы уголовного дела», - пояснили в Следственном комитете. 
Железнодорожный районный суд приговорил бывшего врача «Электроники» к 1,5 годам колонии-поселения. Заметим, что впервые в Воронеже медику, виновному в гибели пациента, вынесли приговор, связанный с лишением свободы. Кроме того, ему на два года запретили заниматься врачебной деятельностью [4].

В соседнем с Обнинском Жуковском районе суд вынес приговор бывшему врачу станции скорой медицинской помощи местной районной больницы, которую обвиняли в оказании не отвечающих требованиям безопасности жизни услуг, предназначенных для детей в возрасте до шести лет.

Женщина-врач не направила к четырехлетнему ребенку бригаду медиков, а вместо этого давала бабушке мальчика рекомендации по телефону. Причем, как выяснилось, та обращалась в скорую не менее 10 раз. А когда на другой день ребенок все же был доставлен в больницу, спасти его уже не успели, и малыш скончался.

На следствии врач признала, что согласно требованиям приказов Минздрава, она должна была организовать выезд скорой к ребенку на дом, однако, с ее слов, на тот момент не было такой возможности, поскольку все бригады были на выездах. Согласно материалам дела, данная информация своего подтверждения не нашла.

В итоге приговором суда бывшему врачу назначено наказание в виде двух лет лишения свободы условно со штрафом 150 тысяч рублей. Также ее лишили права занимать медицинские должности сроком на два года [3].

Хирурга центральной районной больницы 59-летнего Вячеслава Тубылова приговорили к трем годам лишения свободы условно за смерть двух пациентов вследствие халатности врача, сообщает «Зона права».

Также хирург отстранен на три года от врачебной практики. Согласно материалам дела, в ноябре 2016 года Тубылов 15 дней не осматривал пациента, не назначал ему лечение и не сделал операцию, зная о тяжелом состоянии пациента. В итоге больной скончался от язвенной болезни желудка, которая осложнилась массивной кровопотерей. Суд пришел к выводу, что больной нуждался в операции и имел абсолютные показания для этого, однако врач не сделал этого.

Второй случай произошел 31 декабря прошлого года. Во время нахождения на дежурстве, Тубылов отказался принимать больного с колото-резанной раной и приказал направить пациента в другую больницу. Впоследствии мужчина скончался от большой кровопотери.

Ранее в Нурлатском районе Татарстана за смерть ребенка к полутора годам ограничения свободы приговорили заведующую педиатрическим отделением Нурлатской ЦРБ Резеду Юнусову [7]. 
Белгородский врач, убивший пациента, осужден на 9 лет и 2 месяца.

Инцидент произошел в Городской больнице № 2 г. Белгорода. Медику предъявили обвинение в причинении смерти по неосторожности, затем статью переквалифицировали на более тяжкую - «Умышленное причинение тяжкого вреда здоровью, повлекшее по неосторожности смерть потерпевшего».

Зелендинова приговорили к заключению в колонии строгого режима. Кроме того, 3 года он не сможет заниматься профессиональной деятельностью.

Обвинение требовало для обвиняемого 10,5 лет лишения свободы, адвокаты врача настаивали на условном сроке.

Системы независимых экспертов в стране не существует. У следователя нет выбора, где проводить экспертизу. Он может обратиться либо в региональное бюро судмедэкспертизы, либо в единственное федеральное экспертное учреждение Минздрава России, а там - колоссальная очередь и услуги для регионов платные. В итоге экспертиза растягивается на долгие сроки и высок процент отказов в возбуждении уголовных дел по заявлениям граждан. Сейчас в среднем расследование длится около двух лет и до 77\% подобных расследований прекращается, не дожив до суда. Эксперты заявляют, что в этом кроется высокая степень латентности «медицинских» преступлений и их рост [6].

\section{Выводы}

Следует отметить, что действующее уголовное законодательство в условиях стремительного научно-технического прогресса не соответствует по объему объективным потребностям охраны прав пациента и далеко не совершенно с точки зрения законодательной техники.

Увеличение числа гражданских «врачебных» дел свидетельствует о необходимости определения комплекса мер направленных на защиту врачей от необоснованных претензий пациентов при оказании медицинской помощи и судебных исков. Комплекс мер, направленных на предотвращение возникновения конфликтных ситуаций, необоснованных претензий пациентов к врачам должен включать: высокое качество профессиональной деятельности, высокий уровень медико-правовой грамотности, грамотное оформление медицинской документации, надлежащее объективное информирование пациентов, создание системы страхования работодателем врачей от профессионального риска. 
Без знания правовых норм, регулирующих профессиональную деятельность, врач не может на должном уровне выполнять свои профессиональные обязанности.

По мнению президента Национальной ассоциации медицинского права, профессора Ю.Д. Сергеева: «Юридическая и медицинская практика убедительно свидетельствует, что чем выше правовая культура врачей, тем неукоснительнее выполняются ими профессиональные обязанности, тем выше качество и эффективность лечебнодиагностической помощи населению, тем реальнее обеспечиваются права и законные интересы граждан в сфере здравоохранения». [13].

Рекомендуем каждый случай неблагоприятного исхода оказания медицинской помощи, с разрешения правоохранительных органов, представить к рассмотрению и обсуждению на ведомственном и вневедомственном уровнях (заседаниях врачебных комиссий, клиникоанатомических конференциях, территориальном фонде обязательного медицинского страхования, органах управления здравоохранением).

Необходимо проведение совещаний с руководителями лечебно-профилактических учреждений по обсуждению причин возникновения дефектов и мероприятий по их устранению.

Производство судебно-медицинских экспертиз по уголовным делам о профессиональных преступлениях медицинских работников целесообразно поручать только высококвалифицированным экспертам, обладающим помимо необходимых специальных знаний в области медицины, также достаточными правовыми знаниями, в т.ч. в области медицинского права.

Для целенаправленной подготовки и повышения квалификации экспертов отделов сложных (особо сложных) экспертиз, руководителей учреждений судебно-медицинской экспертизы по вопросам организации и производства экспертиз по материалам уголовных дел о профессиональных преступлениях медицинских работников целесообразна организация на базе единого научно-методического центра специальных циклов (курсов), предусматривающих изучение основ теории права, медицинского права, избранных вопросов уголовного права и процесса применительно к потребностям экспертной работы по данной категории экспертиз.

Юристы-преподаватели СПбГУ полагают, что судебная медицина может быть выведена из подчинения Минздрава с перспективой создания при управлениях СК РФ специализированных отделов, в штат которых войдут сотрудники, получившие как медицинское, так и юридическое образование. Недостаток таких кадров может быть восполнен с помощью программы «Медицинское право» в университетской магистратуре [5]. 
В СК РФ признали, что случаи врачебных ошибок, приводящие к тяжелым последствиям, в последнее время происходят все чаще. Обсуждается предложение внести изменения в УК РФ и ввести ответственность за преступления, совершенные медиками. Об этом по итогам совещания с главой ведомства А. Бастрыкиным заявила официальный представитель СК РФ. Выделение врачебных ошибок, приведших к тяжелым последствиям, в отдельную статью УК РФ, по мнению следователей, позволит объективно вести статистику подобных преступлений, а также своевременно делать выводы, почему в том или ином регионе медицинская халатность распространена больше, чем в других. В Минздраве России инициативу СК РФ поддержали и заявили, что готовы проанализировать расследование инцидентов, связанных с врачебными ошибками. В силовом ведомстве совместно со специалистами Минздрава России также планируют создать обучающие программы для расследования таких преступлений, поскольку следователям придется самим определять, в чем могла быть причина произошедшего: в неверной диагностике, ошибочных методах лечения или несвоевременном оказании пациентам медпомощи.

Помимо прочего, подобные дела нередко затягиваются. Дело не в каком-то злом умысле правоохранительных органов, а в том, что следователи зачастую просто не умеют расследовать подобные специфичные случаи: не знают, как надо выстраивать юридическую практику, общаться с экспертами. Правозащитники уверены, что в случае дополнения УК РФ статьей об ответственности за медицинские ошибки повысится качество расследования дел, потому что следователи больше не будут опираться только лишь на судебно-медицинскую экспертизу. Например, в Татарстане в структуре регионального управления СК РФ создано специальное медицинское подразделение, которое выносит свои экспертные заключения по делам, и это повысило качество расследования дел в регионе.

\section{Список литературы}

1. «Дело врачей». Правозащитник о том, как доказать в суде ошибки медиков. Аргументы и Факты 2017; (13) URL:

http://www.kazan.aif.ru/society/details/lechebnoe_delo_kak_dokazat_narusheniya_v_okazanii_medpomoshchi

2. Всероссийский центр изучения общественного мнения. Официальный сайт. URL: https://wciom.ru/ (3)

3. Емелина И. Безответственному врачу дали условный срок. URL: http://obninsk.name/news15117.htm (10)

4. Зайцев С. Впервые в Воронеже врачу за смерть пациента дали реальный срок. URL: https://moeonline.ru/material/1000240 (9)

5. Когаловский В. Следователей начали обучать медицинскому праву. Медвестник URL: https://medvestnik.ru/content/news/Sledovatelei-nachali-obuchat-medicinskomu-pravu.html (14)

6. Козлова Н. Умер по халатности. Российская газета URL: https://rg.ru/2012/10/29/vrachi-site.html (12)

7. Лушкин А. Врачу в Татарстане дали условный срок за смерть двух пациентов. URL: https://inkazan.ru/news/incident/09-08-2017/vrachu-v-tatarstane-dali-uslovnyy-srok-za-smert-dvuh-patsientov (11) 
8. Люльчак Е. Почему врачи бегут из профессии. Мир новостей URL: https://mirnov.ru/obshchestvo/pochemuvrachi-begut-iz-professii.html (6).

9. Медицинское право России: материалы всероссийской научно-практической конференции. М.: Национальный институт медицинского права, 2015. С. 132. (1)

10. Нестерович И. Ю. Уголовная ответственность медицинских работников как вид юридической ответственности. Актуальные вопросы юридических наук: материалы III Международной научной конференции (Чита, апрель 2017 г.). Чита: Молодой ученый, 2017. С. 136-139. (2)

11. Отчет Федерального Фонда обязательного медицинского страхования, 2015. С. 476. (4)

12. Подмосковью не хватает $30 \%$ педиатров. Вадемекум URL:

https://vademec.ru/news/2017/08/31/podmoskovyu-ne-khvataet-30-pediatrov/ (6)

13. Сергеев Ю.Д., Ерофеев С.В. Неблагоприятный исход оказания медицинской помощи. - М.: 2001. С. 14. (13)

14. Статистика врачебных ошибок. URL: http://vawilon.ru/statistika-vrachebnyh-oshibok/ (5)

\title{
Crimes committed by medical workers as a result of improper performance of their professional duties (based on the case-law of the European part of Russia 2015-2017)
}

\author{
Grishin S. M. \\ Candidate of Law, Lawyer of the Moscow bar, lecturer at the Higher School of Economics
}

\section{Summary}

The article, based on factual materials, considers the problem of crimes, resulting from improper performance by medics of their professional duties. The shortcomings of criminal statistics that do not allow creating an integral picture of the situation in the area developing in the country are analyzed, difficulties are noted with the identification of such crimes and the bringing of the perpetrators to criminal liability. The analysis of separate sentences in respect of doctors, through the fault of which the patients were killed, is given. The conclusion is made that the existing criminal legislation does not correspond to the objective needs of protecting the rights of the patient, and proposals are made to improve the effectiveness of forensic medical examinations in criminal cases on professional crimes of medical workers.

Key words: crimes with serious consequences, medical workers, crime statistics, medical error, forensic medical examination

\section{References}

1. «Delo vrachej». Pravozashchitnik o tom, kak dokazat' v sude oshibki medikov ["The case of doctors." The human rights activist on how to prove in the court mistakes of doctors] Argumenty i Fakty 2017; (13) Available at: http://www.kazan.aif.ru/society/details/lechebnoe_delo_kak_dokazat_narusheniya_v_okazanii_medpomoshchi (In Russ.).

2. Russian Public Opinion Research Center (VCIOM). Official web-site. Available at: https://wciom.ru/ (In Russ.).

3. Emelina I. Bezotvetstvennomu vrachu dali uslovnyj srok [The irresponsible doctor was given a suspended sentence]. Available at: http://obninsk.name/news15117.htm (In Russ.). 
4. Zajcev S. Vpervye $v$ Voronezhe vrachu za smert' pacienta dali real'nyj srok [For the first time in Voronezh, a doctor was given a real term for the death of the patient]. Available at: https://moe-online.ru/material/1000240 (In Russ.).

5. Kogalovskij V. Sledovatelej nachali obuchat' medicinskomu pravu [The investigators began to study medical law] Medvestnik. Available at: https://medvestnik.ru/content/news/Sledovatelei-nachali-obuchat-medicinskomupravu.html (In Russ.).

6. Kozlova N. Umer po halatnosti [He died due to negligence]. Rossijskaya Gazeta 2012.10.29. Available at: https://rg.ru/2012/10/29/vrachi-site.html (In Russ.).

7. Lushkin A. Vrachu v Tatarstane dali uslovnyj srok za smert' dvuh pacientov [The doctor in Tatarstan was given a suspended sentence for the death of two patients]. Available at: https://inkazan.ru/news/incident/09-082017/vrachu-v-tatarstane-dali-uslovnyy-srok-za-smert-dvuh-patsientov (In Russ.).

8. Lyul'chak E. Pochemu vrachi begut iz professii? [Why Doctors Flee from the Profession?]. Mir novostej. Available at: https://mirnov.ru/obshchestvo/pochemu-vrachi-begut-iz-professii.html (In Russ.).

9. Medicinskoe pravo Rossii: materialy vserossijskoj nauchno-prakticheskoj konferencii [Medical Law of Russia: Proceedings of the National Scientific and Practical Conference]. Moscow: Nacional'nyj institut medicinskogo prava, 2015. (In Russ.).

10. Nesterovich I. Y. Ugolovnaya otvetstvennost' medicinskih rabotnikov kak vid yuridicheskoj otvetstvennosti. Aktual'nye voprosy yuridicheskih nauk: materialy III Mezhdunarodnoj nauchnoj konferencii (Chita, aprel' 2017 g.) [Criminal liability of medical workers as a type of legal liability. In Actual issues of Jurisprudence: materials of the III International Scientific Conference (City of Chita, April 2017)]. Chita: Molodoj uchenyj, 2017: 136-139. (In Russ.).

11. Otchet Federal'nogo Fonda obyazatel'nogo medicinskogo strahovaniya [Report of the Federal Mandatory Medical Insurance Fund]. Moscow: 2015. (In Russ.).

12. Podmoskov'yu ne hvataet $30 \%$ pediatrov [Moscow region is lacking $30 \%$ of pediatricians]. Vademekum. Available at: https://vademec.ru/news/2017/08/31/podmoskovyu-ne-khvataet-30-pediatrov/ (In Russ.).

13. Sergeev Y.D., Erofeev S.V. Neblagopriyatnyj iskhod okazaniya medicinskoj pomoshchi [Unfavorable outcome of medical care]. Moscow: 2001. (In Russ.).

14. Statistika vrachebnyh oshibok [Statistics of medical errors]. Available at: http://vawilon.ru/statistikavrachebnyh-oshibok/ (In Russ.). 